OPEN ACCESS

Edited by:

Abd El-Latif Hesham,

Assiut University, Egypt

Reviewed by:

Giovanna Suzzi,

Università di Teramo, Italy

${ }^{*}$ Correspondence:

Pradeep Kuma

pkbiotech@gmail.com

Verinder Wahla

virender.wahla@gkv.ac.in

Irfan A. Rather

rather@ynu.ac.kr

${ }^{\dagger}$ These authors have contributed equally to this work.

Specialty section:

This article was submitted to

Food Microbiology,

a section of the journal

Frontiers in Microbiology

Received: 25 September 2017 Accepted: 04 December 2017 Published: 12 December 2017

Citation:

Sing T, Shukla S, Kumar P, Wahla V, Bajpai VK and Rather IA (2017)

Corrigendum: Application of Nanotechnology in Food Science: Perception and Overview.

Front. Microbiol. 8:2517. doi: 10.3389/fmicb.2017.02517

\section{Corrigendum: Application of Nanotechnology in Food Science: Perception and Overview}

\author{
Trepti Sing ${ }^{1+}$, Shruti Shukla ${ }^{2 \dagger}$, Pradeep Kumar ${ }^{3 *}$, Verinder Wahla ${ }^{1 *}$, Vivek K. Bajpai ${ }^{4}$ and \\ Irfan A. Rather ${ }^{4 *}$ \\ ${ }^{1}$ Department of Microbiology, Gurukula Kangri University, Haridwar, India, ${ }^{2}$ Department of Energy and Materials Engineering, \\ Dongguk University-Seoul, Seoul, South Korea, ${ }^{3}$ Department of Forestry, North Eastern Regional Institute of Science and \\ Technology, Itanagar, India, ${ }^{4}$ Department of Applied Microbiology and Biotechnology, Yeungnam University, Gyeongsan-si, \\ South Korea
}

Keywords: nanoparticles, food safety, food preservation, functional food, food nutrition, nano-processed food product

\section{A corrigendum on}

Application of Nanotechnology in Food Science: Perception and Overview by Singh, T., Shukla, S., Kumar, P., Wahla, V., and Bajpai, V. K. (2017). Front. Microbiol. 8:1501. doi: 10.3389/fmicb.2017.01501

Irfan A. Rather was not included as an author in the published article. The authors apologize for this error and state that this does not change the scientific conclusions of the article in any way.

The original article has been updated.

\section{AUTHOR CONTRIBUTIONS}

TS and SS designed, conceived, and wrote the manuscript. PK helped in writing and editing. VW, $\mathrm{VB}$, and IR critically reviewed, edited, and finalized the manuscript for submission.

Conflict of Interest Statement: The authors declare that the research was conducted in the absence of any commercial or financial relationships that could be construed as a potential conflict of interest.

Copyright (c) 2017 Sing, Shukla, Kumar, Wahla, Bajpai and Rather. This is an open-access article distributed under the terms of the Creative Commons Attribution License (CC BY). The use, distribution or reproduction in other forums is permitted, provided the original author(s) or licensor are credited and that the original publication in this journal is cited, in accordance with accepted academic practice. No use, distribution or reproduction is permitted which does not comply with these terms. 